\title{
NOVOS CONCEITOS EM NUTRIÇÃOO. Reflexões a respeito do elo dieta e saúde
}

\author{
Rebeca Carlota de ANGELIS*
}

RESUMO - A respeito do elo dieta-saúde, discutem-se os efeitos fisiológicos de alguns alimentos na redução de riscos de doenças degenerativas tais como enfermidades cardiovasculares e certos tipos de câncer. O novo conceito de alimento funcional com efeitos protetores e preventivos é apresentado com alguns exemplos altamente estudados cientificamente. Entre estes a proteção de osteoporose, através de fitoestrôgenos da soja, os aspectos protetores do azeite de oliva e as interferências do método de extração do azeite. Sumarizam-se algumas condutas gerais para obter os nutrientes adequados e suficientes para uma dieta saudável, protetora e preventiva.

DESCRITORES - Dieta. Alimentos. Hábitos alimentares. Promoção da saúde.

\section{EFEITOS FISIOLÓGICOS DE ALIMENTOS: REDUÇÃO DE RISCOS DE DOENÇAS DEGENERATIVAS}

As evidências epidemiológicas estão continuamente providenciando recomendações para que as pessoas aumentem o consumo de frutas e verduras como medida preventiva para reduzir os riscos de diversas doenças degenerativas. Existem altíssimas correlações de efeitos benéficos de nutrientes essenciais, ou não, que podem modificar processos celulares, com efeitos fisiológicos protetores (Tabela 1).
Muitos compostos encontrados nos alimentos são responsáveis por efeitos benéficos observados em indivíduos que os consomem. Assim, por exemplo, o alho que contem compostos- alil, que enriquecem o sabor dos alimentos, mas também são repelentes contra insetos, além de reduzirem riscos de câncer e enfermidades cardíacas ${ }^{(2)}$.

Outros compostos importantes são os carotenóides, encontrados em frutas e verduras; indóis e tiocianatos de plantas crucíferas, tais como as couves, apresentam propriedades protetoras, como foi verificado em papilomatose respiratória ${ }^{(4)}$.

TABELA 1 - Efeitos fisiológicos de alimentos (alguns exemplos)

\begin{tabular}{ll}
\hline ALIMENTO & EFEITOS FISIOLÓGICOS \\
\hline maçã, cevada, cenoura, berinjela, cebola, soja & reduzem os lipídios plasmáticos \\
alho, beterraba, couves, soja & facilitam a detoxificação \\
ginseng, aveia, salsa & anti-inflamatório \\
alho, cebola, chá verde & antimicrobial \\
soja, couve & fitoestrogênico; antioxidante \\
laranja, chá verde, alho & antiproliferativo \\
\hline (dados extraídos de Milner $\left.\mathrm{JA}^{(3)}\right)$ &
\end{tabular}

Química. Professora Associada do Instituto de Ciências Biomédicas da Universidade de São Paulo. Nutricionista Registrada, Nutrition Society, Inglaterra. Endereço para correspondência: Dra. Rebeca Carlota de Angelis - Al. Min. Rocha Azevedo, 644 - 01410-000 - São Paulo,SP. 


\section{CONCEITO DE ALIMENTOS FUNCIONAIS}

Este novo conceito de alimentos promotores de boa saúde está emergindo como uma nova fronteira no desafio dos profissionais de nutrição e introduzindo a necessidade dos nutrientes tradicionais, como estabelecido ao longo de todos os anos de estudos da Nutrição, mas muito ampliada para o conceito nutrientes preventivos.

Nutrientes são necessários para o desenvolvimento e crescimento normais dos indivíduos. Mas não é somente para todas essas necessidades, é preciso também, proteger os indivíduos contra os riscos por agressões genéticas e do meio ambiente, incluindo os hábitos alimentares, reduzindo riscos que poderiam ser minimizados ou, protelados, através de uma nutrição preventiva, iniciada logo após o desmame e continuada ao longo de toda a vida. Obviamente, que não se proibe o consumo de alimentos menos recomendados, mas é necessária moderação.

É neste ponto que outros componentes dos alimentos, não somente os nutrientes tradicionais, devem também, fazer parte da alimentação. Estes compostos dos alimentos que existem em alimentos e que não são os nutrientes clássicos, mas apresentam propriedades funcionais benéficas, além dos efeitos tradicionais dos nutrientes, devem ser consumidos normalmente.

\section{OSTEOPOROSE E SOJA}

As terapias de tratamento e prevenção de osteoporose em mulheres pós-menopausa incluem reposição hormonal. Estes tratamentos são discutíveis pelo aumento de risco de câncer de mama, e mesmo que estes efeitos não tivessem sido completamente comprovados, observou-se que a substituição deste tratamento com isoflavonas da soja teve resultados bem promissores na redução da perda óssea. Isto ocorre, pois as isoflavonas, especialmente certos tipos destas, na forma de agliconados, apresenta efeito de fito-hormônio, ou seja, estes compostos atuam como estrógenos, porém, sem os possíveis efeitos colaterais destes. Isto ocorre, pois a isoflavona entra nos locais receptores de estrógenos e atuam como estes, conhecidos pois, como fitoestrógenos.

Em mulheres pós-menopáusa tratadas com $80 \mathrm{mg}$ de isoflavona isolada de soja/dia, houve diminuição significativa da perda óssea lombar ${ }^{(1)}$.

\section{ÁCIDO OLÉICO - ASPECTOS PROTETORES}

A dieta mais recomendada como saudável para as populações, principalmente com a meta de reduzir a prevalência de enfermidades cardiovasculares, é a consumida rotineiramente por populações da região do Mediterrâneo, especialmente da década de 1960-70. Hoje, por vários motivos, houve diversas modificações para uma escolha de alimentos menos saudáveis.
O denominador comum da chamada dieta do Mediterrâneo é: maior ingestão de frutas e verduras, com consumo de vinho tinto e azeite de oliva.

Estes elementos foram recomendados às populações como mais saudáveis e preventivos.

Muitos estudos comprovaram os efeitos benéficos do consumo moderado de vinho tinto, não vinho branco ou álcool, na efetiva redução da oxidação do LDL-colesterol (que é a forma que abre as portas a processos de aterosclerose). O mesmo perfil foi correlacionado ao consumo do azeite de oliva, atribuído ao seu conteúdo de ácido oléico. O ácido oléico é um ácido graxo monoinsaturado, que foi por muito tempo, considerado fundamental pelas propriedades benéficas na redução da oxidação do LDL-colesterol, a forma aterogênica.

Outros óleos, também monoinsaturados, poderiam ter as mesmas qualidades protetoras, mas parece que não é bem assim.

O azeite extraído de olivas contem o ácido oléico, mas também outros compostos destas sementes e ainda, dependendo do processamento para a obtenção do óleo, outros fatores podem interferir.

O azeite extra virgem é o único que não é extraído por solventes, mas é obtido por compressão da oliva a frio, o que não altera a natureza da semente.

Este azeite, no amadurecimento, conserva melhor seus componentes, entre os quais, os polifenóis agliconados, característicos pelo odor do azeite.

No entanto, quando o processamento inclui o uso de solventes (azeites refinados), boa parte destes compostos fenólicos são perdidos. Isto ocorre também quando o azeite é alcalinizado para reduzir acidez.

Portanto, os efeitos benéficos do azeite de oliva irão depender do uso do óleo extra virgem, especialmente por seu conteúdo de polifenóis e com os seguintes efeitos principais: 1. potente inibidor de radicais livres; 2. inibidores da oxidação de LDL-colesterol; 3. inibidores de agregação plaquetária; 4 . antitrombóticos ${ }^{(5)}$.

Este trabalho demonstra que os efeitos protetores do azeite de oliva estão correlacionados ao seu conteúdo de ácido graxo monoinsaturado, mas especialmente aos compostos bioativos contidos nele: os polifenóis ativos, funcionais, protegendo a saúde.

E como mensagem: preferir o azeite de oliva não tratado com solventes e refinado, mas o extraído diretamente das sementes.

\section{O QUE RECOMENDAR PARA PREVENIR OU, PROTELAR DOENÇAS QUE PODERIAM SER EVITADAS ATRAVÉS DE UMA ALIMENTAÇÃO SAUDÁVEL}

Considerando estes novos aspectos da nutrição, deve-se recomendar atender todas as necessidades de nutrientes essenciais, conforme as indicações tradicionais, mas também, enriquecer a alimentação com fontes de alimentos funcionais. 
Isto pode ser obtido através de uma alimentação amplamente variada, contendo frutas e verduras em boa quantidade (4 a 5 porções/ dia), moderando, porém, o total calórico e de gorduras. Omitir certos alimentos, habitualmente, pode levar a deficiências importantes. A manutenção de exercícios físicos moderados, rotineiramente é de fundamental importância, juntamente com uma alimentação saudável.

TABELA 2 - Exemplos de efeitos promotores(*) e inibidores (-) de câncer de alguns alimentos

\begin{tabular}{llll}
\hline ÓRGÃO & PROMOTOR (+) & MECANISMO & INIBIDOR (-) \\
\hline esôfago & alimentos salgados, álcool & ativação de carcinógenos & vegetais verde-amarelos, chá verde \\
fígado & alcalóides, álcool, frituras, gordura & citotoxicidade, ácidos biliares & farelos, verduras \\
cólon & frituras, aminas, ácidos biliares & ácidos biliares & fibras, verduras \\
mama & frituras, gorduras & balanço hormonal, & verduras, frutas, perda de \\
& & estrôgenos, obesidade & peso, soja , tomate \\
\hline
\end{tabular}

(dados extraídos de Weisburger $\left.\mathrm{JH}^{(6)}\right)$

Angelis RC. New concepts in nutrition: considerations on the connection diet-health. Arq Gastroenterol 2001;38(4):269-271.

ABSTRACT - The physiological effects of several foods are discussed as possible factors reducing the risk of degenerative diseases as cardiovascular and some cancers. The new emmerging concept of functional foods is presented with examples as the phytoestrogens of soya beans. The importance of consuming olive oil is emphatic, but with criticism to the lost of physiological bioactive material during the normal extractions of the olive oil and the refinement. So, much attention is needed. The way to obtain much of these bioactive protectors foods is summarized.

HEADINGS - Diet. Food. Food habits. Health promotions.

\section{REFERÊNCIAS BIBLIOGRÁFICAS}

1. Alekel L, St. Germain A, Peterson C, Hanson KB, Stewart J, TodaT. Isoflavonerich protein isolate attenuates bone loss in the lumbar spine of perimenopausal women. Am J Clin Nutr 2000;72:844-52.

2. De Angelis RC. Guia global alimentar. In: De Angelis RC. Fome oculta. Impacto para a população do Brasil. Rio de Janeiro: Atheneu; 1999. cap.33.

3. Milner JA. Functional foods: the US perspective. Am J Clin Nutr 2000;71 Suppl. $6: 1654$ S-9S
4. Rosen CA, Woodson GE, Thompson JW, Hengesteg AP, Bradlow HL. Preliminary results of the use of 3-carbinol for recurrent respiratory papillomatosis. Otolaryngol Head Neck Surg 1998;18:810-5.

5. Visioli F, Galli C. Olive oil: more than just oleic acid. Am J Clin Nutr 2000;72:853.

6. Weisburger JH. Approaches for chronic disease prevention based on current understanding of underlying mechanisms. Am J Clin Nutr 2000;71 Suppl.6:1710S$4 \mathrm{~S}$.

Recebido em 22/12/2000 Aprovado em 13/2/200 